Document downloaded from:

http://hdl.handle.net/10251/52339

This paper must be cited as:

Ferre Vilaplana, A.; Gisbert, R.; Herrero, E. (2014). On the electrochemical properties of platinum stepped surfaces vicinal to the (100) pole. A computational study. Electrochimica Acta. 125:666-673. doi:10.1016/j.electacta.2014.01.138.

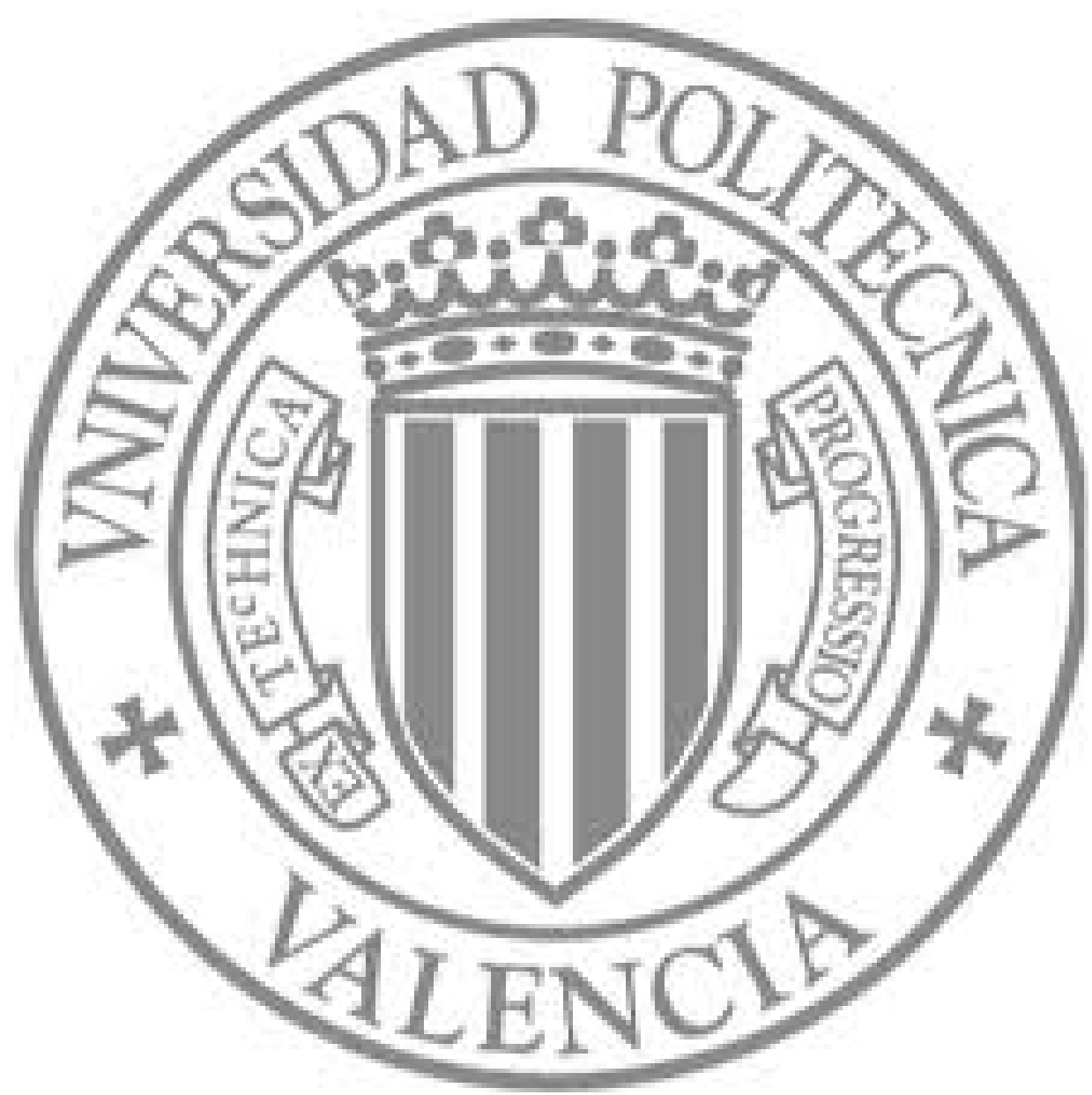

The final publication is available at

http://dx.doi.org/10.1016/j.electacta.2014.01.138

Copyright Elsevier 


\section{Accepted Manuscript}

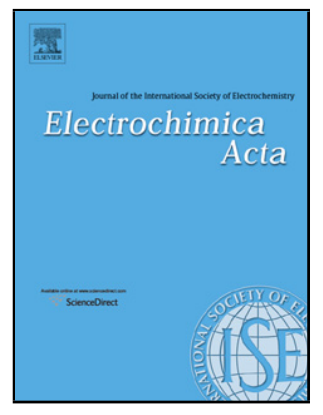

Title: On the electrochemical properties of platinum stepped surfaces vicinal to the (100) pole. A computational study

Author: Adolfo Ferre-Vilaplana Ruben Gisbert Enrique Herrero

PII: S0013-4686(14)00271-0

DOI: http://dx.doi.org/doi:10.1016/j.electacta.2014.01.138

Reference: EA 22131

To appear in: $\quad$ Electrochimica Acta

Received date: $\quad$ 27-10-2013

Revised date: $\quad$ 21-12-2013

Accepted date: $\quad$ 27-1-2014

Please cite this article as: Adolfo Ferre-VilaplanaRuben GisbertEnrique Herrero On the electrochemical properties of platinum stepped surfaces vicinal to the (100) pole. A computational study (2014), http://dx.doi.org/10.1016/j.electacta.2014.01.138

This is a PDF file of an unedited manuscript that has been accepted for publication. As a service to our customers we are providing this early version of the manuscript. The manuscript will undergo copyediting, typesetting, and review of the resulting proof before it is published in its final form. Please note that during the production process errors may be discovered which could affect the content, and all legal disclaimers that apply to the journal pertain. 


\title{
On the electrochemical properties of platinum stepped surfaces vicinal to the (100) pole.
}

\author{
A computational study. \\ Adolfo Ferre-Vilaplana ${ }^{1}$, Ruben Gisbert ${ }^{2}$ and Enrique Herrero ${ }^{2 *}$ \\ ${ }^{1}$ Instituto Tecnológico de Informática, Ciudad Politécnica de la Innovación, Camino de Vera \\ s/n, E-46022 Valencia, Spain, and Departamento de Sistemas Informáticos y Computación, \\ Escuela Politécnica Superior de Alcoy, Universidad Politécnica de Valencia, Plaza Ferrándiz \\ y Carbonell s/n, E-03801 Alcoy, Spain \\ ${ }^{2}$ Instituto de Electroquímica Universidad de Alicante, Apdo. 99, E-03080 Alicante, Spain. \\ *e-mail address: herrero@ua.es
}

\begin{abstract}
.
DFT studies on platinum stepped surfaces have been carried out in order to understand the differences in the electrochemical behavior between the surfaces with (111) and (100) terraces. Thus, adsorption energies of different species on selected surfaces have been computed. For the adsorption of $\mathrm{Bi}$ and $\mathrm{Cu}$ on the $\operatorname{Pt}(553)$ and $\operatorname{Pt}(711)$ surfaces, it has been found that that the adsorption energy on the site corresponding to the step decoration for the $\operatorname{Pt}(553)$ surface is ca. $0.5 \mathrm{eV}$ higher than that calculated on the (111) terrace sites. On the other hand, there is no preferential adsorption site for $\mathrm{Cu}$ or $\mathrm{Bi}$ on the $\mathrm{Pt}(711)$ surface, since the energy differences between the different sites on this stepped surface with (100) terraces are very small. $\mathrm{CO}$ and $\mathrm{OH}$ adsorption on the surface with (100) terraces, namely the $\mathrm{Pt}(100)$, the $\operatorname{Pt}(711)$ and the $\operatorname{Pt}(510)$ surfaces, have been also investigated. The energy differences between step sites and terrace sites for both surfaces is very small, ca. $0.2 \mathrm{eV}$ for $\mathrm{OH}$ adsorption and $<0.1 \mathrm{eV}$ for $\mathrm{CO}$ adsorption. For $\mathrm{OH}$, the preferred adsorption mode is a bridge mode, whereas the adsorption energy for the on top and bridge configurations of $\mathrm{CO}$ are similar on those surfaces. The comparison with previous DFT calculations indicates that the
\end{abstract}


perturbation created by the step on the (100) terrace is significantly smaller than that created on the (111) terraces. Thus, the modification of the electrochemical properties produced by the presence of a step in the (100) terrace is minor, in agreement with the experimental results.

Keywords: Stepped platinum surfaces, step decoration, $\mathrm{OH}$ adsorption, $\mathrm{CO}$ adsorption, electrochemical reactivity.

\section{Introduction.}

Reactions rates in catalytic and electrocatalytic processes strongly depend on the nature of the interactions between reactants (or intermediates) and the surfaces exposed by catalysts, which, in turn, depend on the composition and structure thereof. This is clearly the case of the reactions involved in fuel cells. Both the oxidation of the possible fuels (hydrogen, methanol, formic acid, ethanol...) and the reduction of oxygen strongly depend on the composition and structure of the electrode materials.

For the reactions of fuel cells, platinum is the pure metal with the overall highest catalytic activity. For that reason, its electrochemical behavior has been extensively studied [1-3]. When a detailed analysis of the effects of the surface structure in the electrochemical reactivity is pursued, platinum single crystal electrodes are normally used. This type of electrodes, with a very well defined structure, are very helpful to demonstrate how the surface structure affects the reactivity for a given reaction. From the pioneering works of Clavilier, it was clear that the electrochemical reactivity strongly depends on the surface structure of the platinum electrode [4-7]. In those studies, the so called low index planes were used, that is, $\operatorname{Pt}(111), \operatorname{Pt}(110)$ and $\operatorname{Pt}(100)$ surfaces. Those surfaces contain only one type of site, which help in understanding the elementary steps of those reactions. The presence of only one type 
of site on the surface simplifies the complexity of the system and allows establishing qualitative and quantitative correlations between site and reactivity $[8,9]$.

Although low index planes are very useful in fundamental studies, the surface structure of the real surfaces are far from the ideal low index planes. For practical electrodes, those composed by nanoparticles, their surfaces contain small ordered domains with a (100) or (111) symmetry separated by a series of atoms with a low coordination number. Although the behavior of the long-range ordered (100) or (111) domains can be assimilated to that of the (111) or (100) surfaces, the behavior of small domains and atoms with low coordination number cannot be directly correlated to the ideal basal planes. It is clear that more complex models are required to understand those practical electrodes. The use of stepped surfaces can help to bridge the gap between real surfaces and low index planes. Stepped surfaces contain terraces with a (111) or (100) symmetry separated by monoatomic rows of steps with a given symmetry. The terraces can be used to understand the electrochemical reactivity of the ordered domains in the nanoparticles. On the other hand, the step sites, which are composed by atoms with a low coordination number, serve as models for rest of the atoms in the surface of the nanoparticle. Thus, the different adsorption energy of hydrogen on the (100) and (111) terraces and the different step sites results in voltammetric peaks at different electrode potential. These signals have been used to elucidate the surface structure of the nanoparticles $[10,11]$

As in the case of the nanoparticles, the reactivity of the stepped surfaces is determined by the width and symmetry of the terrace and the symmetry of the step site. By changing the terrace width, the effect of the size of the ordered domain can be studied. For reactions very dependent on the symmetry of the terrace site, significant effects of the ordered domain size have been found. For instance, the ammonia oxidation reaction in alkaline media only occurs at a significant rate on well-ordered $\operatorname{Pt}(100)$ electrodes [12]. This fact explains the reactivity 
of the nanoparticle electrodes for this reaction, so that the highest activity is found for platinum nanoparticles with a significant ratio of large (100) domains on the surface of the nanoparticles [13]. The presence of the steps also modifies the reactivity of the electrode. For the surfaces vicinal to the (111) stereographic pole, that is, those containing terraces with (111) symmetry, significant effects in reactivity of the surface have been found. For those surfaces, the step sites are the active sites on these surfaces for the oxidation of adsorbed CO [14], the cleavage of the C-C bond in the ethanol oxidation reaction [15-18], or the formation of $\mathrm{CO}$ in the formic acid oxidation reaction [19-21], whereas the (111) terrace sites have a negligible activity for those processes. On the other hand, for the surfaces vicinal to the (100) pole, the reactivity of the (100) domains is much less affected by the presence of the steps. The only significant exceptions are the ammonia oxidation reaction [12] o the nitrite/nitrate reduction reaction [22]. For those reactions, an ensemble of sites with (100) symmetry is probably required, as in the case of dimethyl ether oxidation [23]. For instance, the currents for formic acid oxidation [24], methanol oxidation [25], ethanol [23], dimethyl ether [23] or oxygen reduction [26-28] are almost unaffected by the presence of steps on the (100) terraces, especially for surfaces with long terraces.

In order to understand the aforementioned differences in reactivity, DFT calculations were carried out to provide explanations for a broad collection of experimental results. Four processes were considered, because they can serve as models to understand more complex reactions: the deposition of $\mathrm{Bi}$ or $\mathrm{Cu}$, and the adsorption of $\mathrm{CO}$ and $\mathrm{OH}$, on different platinum stepped surfaces with (100) and (111) terraces. $\mathrm{OH}$ and $\mathrm{CO}$ adsorptions are probes that can be used to determine adsorption properties of different sites, and are intermediates in fuel cell reactions, and $\mathrm{Bi}$ or $\mathrm{Cu}$ deposition can be used as a probe of the modification of the properties on the terrace created by the appearance of a step. For the surfaces with (111) symmetry terraces the surface $\operatorname{Pt}(553)$ was selected. This surface has five atom-wide terraces separated 
by (111) monoatomic steps and can be named as $\operatorname{Pt}(\mathrm{s})[5(111) \times(111)]$. Since the (111) step on

a (111) terrace site defines a (110) symmetry site, this surface can also termed a $\operatorname{Pt}(s)[4(111) \times(110)]$. Two different surfaces, also with 4 atom wide terraces, have been chosen to study (100) stepped surfaces with (111) and (110) monoatomic steps: $\operatorname{Pt}(711)=\operatorname{Pt}(s)[4(100) \times(111)]$ and $\operatorname{Pt}(510)=\operatorname{Pt}(s)[4(100) \times(110)]$.

\section{Methods}

\subsection{Experimental methods}

Platinum single crystal electrodes were oriented, cut and polished from small single crystal beads ( $2.5 \mathrm{~mm}$ diameter) following the procedure described by Clavilier and coworkers [29]. The electrodes were cleaned by flame annealing, cooled down in $\mathrm{H}_{2} / \mathrm{Ar}$ and protected with water in equilibrium with this gas mixture to prevent contamination before immersion in the electrochemical cell, as described elsewhere [30]. Experiments were carried out in a classical two-compartment electrochemical cell deaerated by using Ar (N50, Air Liquide in all gases used), including a large platinum counter electrode and a reversible hydrogen (N50) electrode (RHE) as reference.

The potential program for the transients was generated with an arbitrary function generator (Rigol, DG3061A) together with a potentiostat (eDAQ EA161) and a digital recorder (eDAQ, ED401). To avoid any interference of the diffusion of formic acid in the reaction rate, stationary experiments were carried out using a hanging meniscus rotating disk configuration at $900 \mathrm{rpm}$ (controlled by a Radiometer CTV 101).

\subsection{Computational methods.}

$\mathrm{Bi}$ and $\mathrm{Cu}$ adsorption energies on different surface sites have been calculated for the stepped surfaces $\operatorname{Pt}(553)$ and $\operatorname{Pt}(711)$, whereas the low index surface $\operatorname{Pt}(100)$ and the stepped 
surfaces $\operatorname{Pt}(510)$ and $\operatorname{Pt}(711)$ have been used for calculating the adsorption energy on different sites for $\mathrm{CO}$ and $\mathrm{OH}$. Running Dmol3 [31], adsorption energies were estimated using DFT under numerical basis sets of double- $\zeta$ quality plus polarization functions [32], DFT semi-core pseudo-potentials (which include scalar relativistic effects) [33] and the GGA-RPBE functional (which was specifically developed for catalysis applications) [34]. Brillouin zones were sampled, under the Monkhorst-Pack method [35], using grids corresponding to distances, in the reciprocal space, of the order of $0.041 / \AA$. Convergence was facilitated by introducing $0.005 \mathrm{Ha}$ of thermal smearing, although energies were extrapolated to $0 \mathrm{~K}$. The effects of non-zero dipole moments in the supercells were cancelled by means of external fields [36].

The $\operatorname{Pt}(553), \operatorname{Pt}(711), \operatorname{Pt}(100)$ and $\operatorname{Pt}(510)$ surfaces were modeled by means of periodic supercells comprising $38,30,16$ and $42 \mathrm{Pt}$ atoms, respectively, corresponding to metal layer thicknesses of $9.45,7.90,6.04$ and $7.90 \AA$, also respectively, and vacuum slabs of $14 \AA$ (figure 1). During optimizations, the bottom 18, 14, 8 and $20 \mathrm{Pt}$ atoms, respectively, were frozen in their bulk crystal locations, meanwhile the remaining 20, 16, 8 and $22 \mathrm{Pt}$ atoms, respectively, were completely relaxed joint to the adsorbates. The shortest distances between adsorbate images were 5.70, 5.70, 5.70 and $8.06 \AA$, respectively. Adsorption energies were calculated as the energy difference between that corresponding to the adsorbent-adsorbate complex, after adsorption, and those corresponding to absorbent and adsorbate, before adsorption. Given that all the investigated supercells are large enough to minimize the interaction between adsorbate images (the shortest distance between adsorbate images being $5.70 \AA$ ), adsorbate energies were estimated in gas phase, and the obtained results used as a fixed reference in each corresponding adsorption energy calculation. For each adsorption site, the position of each adsorbate atom was optimized during the calculation. 


\section{Results.}

\subsection{Adatom adsorption on (111) steps on (100) terraces and (100) steps on (111) terraces.}

The first important difference found in the experimental behavior between the stepped surfaces with (111) and (100) terraces is the possibility of decoration of the step with a foreign adatom. It has been shown that some adatoms are able to decorate the step of a (111) terrace both in electrochemical [37-40] and UHV environments [41-45]. For these adatoms, the initial stages of the deposition process takes place on the step and the deposition on the terrace only occurs when the step has been completely decorated. The preference for the step site in the deposition process has been associated, qualitatively, to the appearance of a dipole in the step due to the Smoluchowski effect [46]. The perturbation created by a step on a terrace generates a surface dipole. The upper part of the step has a partial positive charge and the lower part a partial negative charge. When an electropositive adatom with respect to platinum, such as $\mathrm{Cu}$ or $\mathrm{Bi}$ adsorbs on the surface, transfer part of its charge to the platinum and then the adatom has a partial positive charge [47]. In this way, it has been proposed that these adatoms will tend to adsorb on the lower part of the step, since it has a negatively charge. This mechanism that guides the atom to the step decoration site is also possible on the stepped surfaces with (100) terraces. However, it has been found that preferential step decoration does not occur on those surfaces, since deposition occurs simultaneously on the terrace and on the step $[48,49]$.

These differences are well observed in figures 2 and 3. Figure 2 shows a slow deposition process of $\mathrm{Bi}$ in a $0.5 \mathrm{M} \mathrm{H}_{2} \mathrm{SO}_{4}$ solution for the $\mathrm{Pt}(553)$ surface. This surface contains 4 atom wide terraces with (111) symmetry and a (110) monoatomic step. The solution concentration of $\mathrm{Bi}$ ions is ca. $10^{-5} \mathrm{M}$. Under such conditions, deposition is purely controlled by the diffusion of the species from the bulk solution to the surface, since the reduction process of $\mathrm{Bi}^{3+}$ to $\mathrm{Bi}^{0}$ is thermodynamically favorable in this potential window. Due 
to the slow diffusion rate, the changes in the voltammetric profile of the electrode as the deposition proceeds can be observed. Three characteristic signals can be followed, so that the deposition site can be identified. In the unmodified voltammogram, the peak at $0.13 \mathrm{~V}$ is associated to the hydrogen adsorption/desorption process on the (110) step sites. The signals coming from the terrace can be observed in two different potential regions. Hydrogen adsorption/desorption processes on the terrace take place between the onset of hydrogen evolution and ca. $0.40 \mathrm{~V}$ and give rise to a flat featureless signal. On the other hand, sulfate adsorption on the terrace sites occurs between 0.3 and $0.6 \mathrm{~V}$ [50]. As can be seen, only step sites are covered in the initial stages of $\mathrm{Bi}$ deposition, since the only signal that diminishes is that corresponding to the (110) step sites. This fact clearly shows that the deposition process only occurs on the step sites and complete decoration of the step is possible [19, 20, 39]. Additionally, there is a characteristic signature for the deposition of $\mathrm{Bi}$ on the (111) terrace, the appearance of a redox peak at $0.63 \mathrm{~V}$, which has been used to estimate the amount of (111) terrace sites on any given Pt sample [51]. As can be seen, this signal only appears when the step sites have been completely covered, that is when the peak at $0.13 \mathrm{~V}$ has disappear, proving that $\mathrm{Bi}$ is effectively decorating the step sites. The appearance of this new peak is parallel to the diminution of the terrace sites, as can be seen in the significant diminution of the signals related to the adsorption of sulfate on the (111) terrace. A similar behavior can be observed for $\mathrm{Cu}$ deposition on those electrodes [37].

On the other hand, Bi deposition on $\operatorname{Pt}(11,1,1)=\operatorname{Pt}(s)[6(100) \times(111)]$ surface follows a completely different behavior. On the voltammogram of the $\operatorname{Pt}(11,1,1)$ electrode (figure 3 ), the signals appearing above $0.3 \mathrm{~V}$ are related to the terrace sites far away from the step, whereas the peak at $0.27 \mathrm{~V}$ is related to terrace sites close to the step [52]. Step sites give contributions at potentials below $0.2 \mathrm{~V}[53,54]$. As can be seen, there is a significant diminution of the signal corresponding to the terrace sites in the initial stages of the 
deposition, especially those far away from the step, with a small diminution in the states below $0.3 \mathrm{~V}$, which can be related to step decoration. Clearly, deposition for this electrode is occurring both in the step and terrace sites.

In order to understand the origin of these differences, DFT calculations were carried out. In these calculations, the energy for $\mathrm{Bi}$ or $\mathrm{Cu}$ adsorption on different sites on the $\mathrm{Pt}(553)$ and $\operatorname{Pt}(711)$ surfaces were examined. The different adsorption sites studied for both surfaces are shown in figure 4. For the $\operatorname{Pt}(553)$ surface, fcc and hcp hollow sites on different terrace positions were considered, whereas only hollow sites for the (100) terrace were studied. The calculated adsorption energies for $\mathrm{Bi}$ and $\mathrm{Cu}$ on the different adsorption sites are given in tables 1 and 2. The sites corresponding to step decoration are the fcc 4 and $\mathrm{H} 3$ for the $\operatorname{Pt}(553)$ and $\operatorname{Pt}(711)$ surfaces, respectively. As can be observed, there is a significant difference between energy for the adsorption on the fcc4 site for the $\operatorname{Pt}(553)$ surface and the adsorption energy on the rest of the sites. The adsorption in this site is ca. $0.5 \mathrm{eV}$ more favorable (for both $\mathrm{Bi}$ and $\mathrm{Cu}$ ) than that on the remaining terrace sites. This fact implies that the step decoration is a process energetically favorable. On the other hand, there is no significant difference in the adsorption energy for the different sites on the $\operatorname{Pt}(711)$ surface. For bismuth the differences between the sites lies within the error of the calculations, whereas for $\mathrm{Cu}$ adsorption is only $0.1 \mathrm{eV}$. It should be mentioned that the overall energetics of the step decoration is not determined by the adsorption energy of a single atom, but by that of the corresponding extended 1D lattice. However, the overall energy of this process is related to the energy of a single atom adsorption. Also, this energy is related to the initial stages for the 1D lattice formation, and for that reason, it can be used as a parameter to determine the possible formation of a decorated surface.

The small differences in the adsorption energy of the adatoms between the sites in the $\operatorname{Pt}(711)$ surface is not anticipated a priori. It could be expected that a higher number of nearest 
neighbors would favor deposition on those sites, due to a larger interaction with the surface. When deposited in the $\mathrm{H} 1$ or $\mathrm{H} 2$ site, $\mathrm{Bi}$ or $\mathrm{Cu}$ have $4 \mathrm{Pt}$ nearest neighbor shells, whereas there are only 3 nearest neighbors for the adatom deposited on the fcc1-3 or hcp1-3sites. Thus, the obtained adsorption energy on the (100) terrace plane is more favorable. It should be highlighted that, in the case of the $\operatorname{Pt}(553)$, there is no significant difference between the fcc1-3 sites and the hcp1-3 sites. These sites only differ in the number of atoms in the second shell, suggesting that the interactions with the nearest neighbors is the main contribution to the total energy in those sites. For sites that correspond to the step decoration, the H3 and fcc4 sites, the number of Pt nearest neighbors is 5 in both cases. For the $\mathrm{Pt}(553)$ surface, there is a significant increase in the adsorption energy for this site with respect to the terrace sites, which could be associated to the increase in the number of nearest neighbors. However, such increase is not observed for the $\operatorname{Pt}(711)$ surface. Strain effects can play a role on those cases, because $\mathrm{Bi}$ or $\mathrm{Cu}$ adatoms should accommodate to a lattice in which the distances are different from that of the bulk $\mathrm{Bi}$ or $\mathrm{Cu}$ metal. Anyhow, the adsorption energy for the fcc 4 site is still lower than that corresponding to the $\mathrm{H} 3$ site.

These DFT results clearly indicate that the different behavior of the stepped surfaces with (100) and (111) terraces has a thermodynamic origin. Adsorption on the (110) step sites in (111) terraces is energetically favorable when compared to the (111) terrace sites, whereas the energy of adsorption on the (111) step site in (100) terraces is very similar to that on the (100) terrace. Thus, the experiments in figures 2 and 3 can be easily explained. The deposition process on those surfaces is controlled by the diffusion rate of $\mathrm{Bi}$ species from the bulk solution to the surface. As aforementioned, it can be considered that the Bi ions reaching the surface are immediately reduced to $\mathrm{Bi}^{0}$ in the electrode potential window in which those figures are recorded, giving rise to a $\mathrm{Bi}$ adatom on the surface. The deposition process can take place in any site of the surface. However, the higher adsorption energy of the fcc 4 site 
guides the diffusion of the $\mathrm{Bi}$ or $\mathrm{Cu}$ adatom towards the fcc4 site, which is the most energetically favorable site. In this position, the adatom will remain trapped because of the higher adsorption energy, giving rise to a step-decorated surface. This mechanism assumes that the barrier for the adatom diffusion is low, so that the adatom has reached the most favorable position before the next deposition event takes place. On the other hand, for the stepped surfaces with (100) terraces, the differences in the adsorption energy are very small, and therefore, adatoms are not trapped for the sites corresponding to the step decoration and no preferential adsorption takes place.

\subsection{OH adsorption on stepped surfaces with (100) terraces.}

The observed electrocatalytic behavior for the electrodes vicinal to the (100) pole does not differ, in general, from that observed for the $\mathrm{Pt}(100)$ electrode. For instance, the measured currents and intrinsic activity for the oxidation of formic acid on those electrodes is almost equal to that observed for the $\operatorname{Pt}(100)$ electrode [24]. For this particular reaction, the $\operatorname{Pt}(100)$ electrode is very active and the presence of steps does not alter this high activity. Only for surfaces with (100) terraces and a high step density, a clear diminution of the activity is observed. For other reactions, such as methanol or ethanol oxidation the reactivity of this series of stepped surfaces is also very similar. This is in contrast to that observed for the surfaces with (111) terraces, for which significant changes are observed $[15,21,25]$. The similar behavior of the stepped surfaces with (100) terraces clearly indicates that the general reactivity of the step and (100) terrace sites is comparable. Since all these reactions are structure sensitive, which implies that the involved species in the rate determining step of the reaction mechanism are adsorbed, it can be concluded that the adsorption properties of the step and (100) terrace sites are very similar. 
In order to demonstrate that, $\mathrm{OH}$ species have been used as test species to calculate adsorption energies using DFT on the $\operatorname{Pt}(100), \operatorname{Pt}(711)$ and $\operatorname{Pt}(510)$ surfaces. Figure 5 shows all the different adsorption sites considered in the calculation. For the $\mathrm{OH}$ adsorption on the Pt(100) electrode, top (T) and bridge (B) sites have been considered. Since the O-H bond does not lie normal to the surface, there can be an effect of the $\mathrm{OH}$ plane direction in the adsorption energy. For that reason, several orientations of the $\mathrm{OH}$ bond with respect to the surface were calculated. In general, the effect of the $\mathrm{OH}$ bond direction in the adsorption energy is very small for the $\operatorname{Pt}(100)$ surface (the difference is always below $0.02 \mathrm{eV}$ ) and lies within the error of the calculations. This fact clearly suggests that the adsorbed $\mathrm{OH}$ species can rotate freely when it is adsorbed on the surface. Probably, the exact position of the $\mathrm{OH}$ plane will depend on the interactions through hydrogen bonds with the solvent water.

Table 3 gives the calculated adsorption energies for the different sites on the different surfaces. For the stepped surfaces, values for two different $\mathrm{OH}$ orientation are given: the $-\mathrm{i}$ configurations are those in which the hydrogen atom of the $\mathrm{OH}$ species is pointing towards the lower part of the step whereas in the -o configurations, the hydrogen atom is pointing towards the upper part of the step. Due to the anisotropy of the surface, the difference between the $-\mathrm{o}$ and -i configurations for some adsorption sites can be larger than that observed for the $\operatorname{Pt}(100)$ surface, especially in the sites close to the step. For the $\operatorname{Pt}(100)$ surface, (table 3) the most favorable site for the $\mathrm{OH}$ adsorption is the bridge site, whose the adsorption energy is ca. $0.4 \mathrm{eV}$ higher than that measured for top sites. In the stepped surfaces, the same trend can be found and the energy difference between both adsorption geometries in terrace sites is also very close to $0.4 \mathrm{eV}$. It should be remarked that the adsorption energy on the rows 2 to 4 in bridge positions is ca. $2.6 \mathrm{eV}$, the same value found for the $\operatorname{Pt}(100)$ surface, which indicates that the perturbations caused by the step do not affect significantly the terrace sites, even for such small terraces. 
When the energy for adsorbed $\mathrm{OH}$ on the step is calculated, the adsorption on the step atoms for the $\operatorname{Pt}(711)$ is more favorable (ca. $0.3 \mathrm{eV}$ ) than in terrace sites, both for top an bridge sites. Again, the most favorable position for the adsorption of $\mathrm{OH}$ is a bridge site, in which both atoms are in the step row. The difference in adsorption energy between terrace and step sites is lower than that found for surfaces with (111) terraces, for which the difference was between 0.5 and $0.8 \mathrm{eV}$, depending on the step symmetry [55]. This difference in the adsorption energy for $\mathrm{OH}$ can be related to the electrochemical behavior of these electrodes. For the $\mathrm{Pt}(100)$ electrode in perchloric acid solutions, $\mathrm{OH}$ adsorption occurs at ca. $0.42 \mathrm{~V}$, which is very close to the potential of zero total charge of the electrode [53]. On the other hand, the signals corresponding to $\mathrm{OH}$ adsorption on the step sites (for stepped surfaces vicinal to the (100) pole) appear at potentials below $0.15 \mathrm{~V}$, which represent an electrode potential difference of at least $0.27 \mathrm{~V}$, which is very close to the calculated energy difference [53]. A similar situation is observed in alkaline solutions [56], where $\mathrm{OH}$ adsorption on the steps occurs above $0.45 \mathrm{~V}$ and the adsorption of $\mathrm{OH}$ on the steps is occurs below $0.15 \mathrm{~V}$ [56]. These differences in electrode potential are in agreement with those obtained here, which suggest that the presence of explicit water do not alter the relative values of the adsorption energy for $\mathrm{OH}$ on the different sites.

For the $\mathrm{Pt}(510)$ surface, there is no preference for the adsorption of $\mathrm{OH}$ on the step, since the adsorption energy is the same, within the error, for all the bridge sites. Moreover, adsorption on top sites on rows 1 (the step line) and 4 have also comparable energies. This behavior is due to the open nature of the step. In this type of step, the Pt-Pt distance in the step line is $\sqrt{2}$ times that found in the step with (111) symmetry. This fact prevents the adsorption of $\mathrm{OH}$ in a bridge configuration bonded to two atoms in the step line. The only way to adsorb close to the step is in a bridge configuration in the site B12 or on top in site T1. For the site B12, the adsorption energy is very close to that measured in the remaining bridge sites and 
similar to that measured on the $\operatorname{Pt}(100)$ surface and the $\mathrm{B} 12$ site on the $\operatorname{Pt}(711)$ surface. For the $\mathrm{T} 1$ site, the adsorption energy for this site is ca. $0.4 \mathrm{eV}$ higher than that observed for on top sites on the terrace, as observed for the other surface, and this value is comparable to that observed for a bridge site on the terrace. These results clearly indicate that the perturbation caused by the step is restricted to the atoms in the step line.

\subsection{CO adsorption on stepped surfaces with (100) terraces.}

$\mathrm{CO}$ is another molecule that can be used to probe the adsorption and reaction properties of steps. In fact, it appears as a reaction intermediate in the oxidation of small organic molecules such as formic acid, methanol or ethanol. For this molecule, the obtained results are similar to those obtained for $\mathrm{OH}$ adsorption. On the $\mathrm{Pt}(100)$ plane (table 4), the energies are similar for top and bridge sites, in agreement with the FTIR spectra obtained in electrochemical environments [57]. In the FTIR spectra, both bands corresponding to bridge and on top CO have similar intensities. When step are introduced, the adsorption energies are only affected for the sites on the step. However, the energy increase on those sites are around $0.1 \mathrm{~V}$, which can be considered the error of these calculations. The only exception is the T1 site on the $\operatorname{Pt}(510)$ surface, which has an adsorption energy which is ca. $0.15 \mathrm{eV}$ higher than in the rest of the positions. Again, in this case, the difference can be assigned to the open nature of the step line. For $\mathrm{CO}$, there is no significant energy difference between the top and bridge modes, so there is a small increase in adsorption energy for the top position in the step (ca. $0.1 \mathrm{eV}$ ). On the other hand, there is no possibility of adsorption on a bridge site with the two atoms on the step. In conclusion, the perturbation in the surface energy caused by the presence of the step on the (100) terrace does not modify significantly the CO adsorption energy, unlike the results obtained for the surfaces vicinal to the (111) pole [58]. 


\section{Concluding remarks.}

The results presented here clearly show the difference in behavior of the platinum stepped surfaces with (100) terraces and those with (111) terraces. A clear effect in the adsorption energy is observed for the step decoration of $\mathrm{Bi}$ or $\mathrm{Cu}$ or in the $\mathrm{OH}$ and $\mathrm{CO}$ adsorption on the step depending on the terrace symmetry. Using these species, it has been possible to determine the effects of the perturbation created by the step on the surface. Thus, $\mathrm{OH}$ or $\mathrm{CO}$ is preferentially adsorbed on the step sites and the energy difference with respect to (111) terrace sites is between $0.5-07 \mathrm{eV}$ [55]. For the stepped surfaces with (100) terraces, the differences are much smaller: ca. $0.2 \mathrm{eV}$ for $\mathrm{OH}$ adsorption and negligible values for $\mathrm{CO}$. If $\mathrm{CO}$ and $\mathrm{OH}$ probe the sites in the upper part of the step, the deposition of $\mathrm{Bi}$ or $\mathrm{Cu}$ can be used to test the modifications in the lower part of the step (step decoration), since this is the preferred site for the adsorption. Again, there is a significant difference between the surfaces with (111) and (100) terraces. The adsorption energy in the sites corresponding to step decoration is ca. $0.5 \mathrm{eV}$ higher than in the rest of (111) terrace sites, whereas the difference between the step site and the (100) terrace sites is $0-0.1 \mathrm{eV}$. These results clearly indicate that the perturbation in the energy of the surface created by the presence of a step in a (100) terrace is small.

The perturbation created by the step can be explined by the Smoluchoswki effect [46]. Figure 6 displays the calculated electrostatic potentials mapped on electron density isosurfaces (for isosurfaces of the same density value $\rho=0.01 \mathrm{e} / \AA^{3}$ ) for $\operatorname{Pt}(553)$ and $\operatorname{Pt}(711$ ). As can be seen, in both cases, the upper part of the step has a clear positive charge concentrated in the row of atoms on the step whereas a negative charge can be inferred for the terrace part of the step although more evenly distributed. However, the magnitude of this effect, in terms of electrostatic potential, is almost the double for the $\operatorname{Pt}(553)$ surface than that calculated for the $\operatorname{Pt}(711)$ surface. Therefore, figure 6 suggests that the Smluchowski effect is 
the origin of the catalytic behavior of the steps and the parameter that can be used to explain changes in behavior.

In addition, electron density changes are related to work function changes, which are in turn related to another important electrochemical property: the potential of zero charge (PZC) [59]. For gold single crystals, the work function changes for the stepped surfaces with (100) terraces are much smaller than those measured for the surfaces with (111) terraces. This is a consequence of a larger surface dipole created by the presence of the step on a $\mathrm{Au}(111)$ terrace, which is almost one order of magnitude higher than that measured for a vicinal $\operatorname{Au}(100)$ surface $[60,61]$. These results are also consistent with the suggested conclusion, supported by figure 6 .

Thus, the whole of the above described results and conclusions clearly indicate that the perturbation generated by a step on a (100) terrace is small, and therefore, small electrocatalytic changes are expected on those stepped surfaces. And, in fact, the observed electrocatalytic behavior for the stepped surfaces with (100) terraces was very small. If the adsorption properties of the step sites are similar to those of the terrace, the possible interaction with reactants and/or intermediates is comparable and therefore, similar electrocatalytic behavior is found. This is true for the reactivity of small molecules, such as oxygen [26-28] or formic acid [24]. A clear example is the oxygen reduction reaction in alkaline media. For this reaction, the most active surface is the $\operatorname{Pt}(111)$ electrode, and the presence of the steps diminishes its activity, so that the activity of the $\operatorname{Pt}(553)$ electrode is 4 times smaller than that of the $\operatorname{Pt}(111)$ surface. For the surfaces with (100) terraces, the difference between the $\operatorname{Pt}(100)$ electrode and the $\operatorname{Pt}(711)$ is only 1.2 times [28].

The discussed different behavior of the steps on the (111) and (100) terraces also affects the behavior of the $\operatorname{Pt}(100)$ and $\operatorname{Pt}(111)$ electrodes. The large difference in the reactivity of the steps in the (111) terrace with respect to the terrace sites explain why the 
reactivity of the real $\operatorname{Pt}(111)$ electrode is, for some reactions, governed by the number of defects, which behave in a similar way to step sites. Thus, it has been proposed that some reactions on a real $\mathrm{Pt}(111)$ electrode occurs only on the defects, such as $\mathrm{CO}$ oxidation [62], CO formation from formic acid $[19,20]$ or the cleavage of the C-C bond in ethanol oxidation $[15,16]$. Since those reactions does not occur on the ideal $\operatorname{Pt}(111)$ plane, the number of defects clearly affects the reactivity, and significant differences can be observed between $\operatorname{Pt}(111)$ electrodes with different quality. On the other hand, such effects of the defects on the (100) plane have not been observed. It should be highlighted that after the flame annealing process, the surface of the $\operatorname{Pt}(100)$ electrode is reconstructed forming an hexagonal structure. This reconstruction is lifted during the cooling of the electrode in the $\mathrm{H}_{2}$ atmosphere, which leads to a significant amount of defects formed in the surface, as STM results demonstrate $[63,64]$. In spite of the higher number of defects present on this electrode with respect to the $\operatorname{Pt}(111)$ electrode, the preparation conditions and number of defects have a very small effect on the electrochemical behavior of this electrode.

\section{Acknowledgments.}

This work has been financially supported by the MICINN (Spain) (project CTQ2010-16271FEDER) and Generalitat Valenciana (project PROMETEO/2009/045, -FEDER).

\section{References.}

[1] R. Parsons, T. Vandernoot, J. Electroanal. Chem., 257 (1988) 9.

[2] M.T.M. Koper, S.C.S. Lai, E. Herrero, in: M.T.M. Koper (Ed.) Fuel Cell Catalysis, A Surface Science Approach, John Wiley \& Sons, Inc, Hoboken, NJ, 2009, pp. 159.

[3] N.M. Markovic, P.N. Ross, Surf. Sci. Rep., 45 (2002) 117.

[4] J. Clavilier, C. Lamy, J.M. Leger, J. Electroanal. Chem., 125 (1981) 249.

[5] J. Clavilier, R. Parsons, R. Durand, C. Lamy, J.M. Leger, J. Electroanal. Chem., 124 (1981) 321.

[6] C. Lamy, J.M. Leger, J. Clavilier, J. Electroanal. Chem., 135 (1982) 321.

[7] C. Lamy, J.M. Leger, J. Clavilier, R. Parsons, J. Electroanal. Chem., 150 (1983) 71.

[8] J. Clavilier, J. Electroanal. Chem., 236 (1987) 87. 
[9] A. Fernández-Vega, J.M. Feliu, A. Aldaz, J. Clavilier, J. Electroanal. Chem., 305 (1991) 229.

[10] J. Solla-Gullón, P. Rodríguez, E. Herrero, A. Aldaz, J.M. Feliu, Phys. Chem. Chem. Phys., 10 (2008) 1359.

[11] F.J. Vidal-Iglesias, R.M. Aran-Ais, J. Solla-Gullon, E. Herrero, J.M. Feliu, ACS Catal., 2 (2012) 901.

[12] F.J. Vidal-Iglesias, N. Garcia-Araez, V. M ontiel, J.M. Feliu, A. Aldaz, Electrochem. Commun., 5 (2003) 22.

[13] F.J. Vidal-Iglesias, J. Solla-Gullón, P. Rodríguez, E. Herrero, V. M ontiel, J.M. Feliu, A. Aldaz, Electrochem. Commun., 6 (2004) 1080.

[14] N.P. Lebedeva, A. Rodes, J.M. Feliu, M.T.M. Koper, R.A. van Santen, J. Phys. Chem. B, 106 (2002) 9863.

[15] F. Colmati, G. Tremiliosi, E.R. Gonzalez, A. Berna, E. Herrero, J.M . Feliu, Phys. Chem. Chem. Phys., 11 (2009) 9114.

[16] J. Souza-Garcia, E. Herrero, J.M. Feliu, ChemPhysChem, 11 (2010) 1391.

[17] V. Del Colle, J. Souza-Garcia, G. Tremiliosi, E. Herrero, J.M. Feliu, Phys. Chem. Chem. Phys., 13 (2011) 12163.

[18] V. Del Colle, A. Berna, G. Tremiliosi, E. Herrero, J.M. Feliu, Phys. Chem. Chem. Phys., 10 (2008) 3766.

[19] M.D. Maciá, E. Herrero, J.M. Feliu, A. Aldaz, Electrochem. Commun., 1 (1999) 87.

[20] M.D. M aciá, E. Herrero, J.M. Feliu, A. Aldaz, J. Electroanal. Chem., 500 (2001) 498.

[21] V. Grozovski, V. Climent, E. Herrero, J.M. Feliu, Phys. Chem. Chem. Phys., 12 (2010) 8822.

[22] M. Duca, M.C. Figueiredo, V. Climent, P. Rodriguez, J.M. Feliu, M.T.M. Koper, J. Am. Chem. Soc., 133 (2011) 10928.

[23] H. Li, F. Calle-Vallejo, M.J. Kolb, Y. Kwon, Y. Li, M.T.M. Koper, J. Am. Chem. Soc., 135 (2013) 14329.

[24] V. Grozovski, V. Climent, E. Herrero, J.M. Feliu, ChemPhysChem, 10 (2009) 1922.

[25] V. Grozovski, V. Climent, E. Herrero, J.M. Feliu, J. Electroanal. Chem., 662 (2011) 43.

[26] M.D. Maciá, J.M. Campina, E. Herrero, J.M. Feliu, J. Electroanal. Chem., 564 (2004) 141.

[27] A. Kuzume, E. Herrero, J.M. Feliu, J. Electroanal. Chem., 599 (2007) 333.

[28] R. Rizo, E. Herrero, J.M. Feliu, Phys. Chem. Chem. Phys., 15 (2013) 15416.

[29] J. Clavilier, D. Armand, S.G. Sun, M. Petit, J. Electroanal. Chem., 205 (1986) 267.

[30] A. Rodes, K. Elachi, M.A. Zamakhchari, J. Clavilier, J. Electroanal. Chem., 284 (1990) 245.

[31] B. Delley, The Journal of Physical Chemistry, 100 (1996) 6107.

[32] B. Delley, J. Chem. Phys., 92 (1990) 508.

[33] B. Delley, Phys. Rev. B, 66 (2002) 155125.

[34] B. Hammer, L.B. Hansen, J.K. Nørskov, Phys. Rev. B, 59 (1999) 7413.

[35] H.J. Monkhorst, J.D. Pack, Phys. Rev. B, 13 (1976) 5188.

[36] J. Neugebauer, M. Scheffler, Phys. Rev. B, 46 (1992) 16067.

[37] L.J. Buller, E. Herrero, R. Gómez, J.M. Feliu, H.D. Abruna, Journal of the Chemical SocietyFaraday Transactions, 92 (1996) 3757.

[38] P. Berenz, S. Tillmann, H. M assong, H. Baltruschat, Electrochim. Acta, 43 (1998) 3035.

[39] E. Herrero, V. Climent, J.M. Feliu, Electrochem. Commun., 2 (2000) 636.

[40] G. Samjeske, X.Y. Xiao, H. Baltruschat, Langmuir, 18 (2002) 4659.

[41] P. Gambardella, M. Blanc, H. Brune, K. Kuhnke, K. Kern, Phys. Rev. B, 61 (2000) 2254.

[42] P. Gambardella, M. Blanc, L. Burgi, K. Kuhnke, K. Kern, Surf. Sci., 449 (2000) 93.

[43] K. Kuhnke, K. Kern, Journal of Physics Condensed M atter, 15 (2003) S3311.

[44] C. Pint, G. Bozzolo, J.E. Garces, Surf. Sci., 602 (2008) 559.

[45] R. Streber, B. Trankenschuh, J. Schock, C. Papp, H.P. Steinruck, J.S. M cEwen, P. Gaspard, R. Denecke, J. Chem. Phys., 131 (2009).

[46] R. Smoluchowski, Physical Review, 60 (1941) 661. 
[47] W.F. Lin, S.G. Sun, Z.W. Tian, J. Electroanal. Chem., 364 (1994) 1.

[48] R. Francke, V. Climent, H. Baltruschat, J.M. Feliu, J. Electroanal. Chem., 624 (2008) 228.

[49] R. Gisbert, V. Climent, E. Herrero, J.M. Feliu, Journal of Electrochemistry, 18 (2012) 410.

[50] E. Herrero, J. M ostany, J.M. Feliu, J. Lipkowski, J. Electroanal. Chem., 534 (2002) 79.

[51] P. Rodríguez, J. Solla-Gullón, F.J. Vidal-Iglesias, E. Herrero, A. Aldaz, J.M. Feliu, Anal. Chem., 77 (2005) 5317.

[52] J.M. Feliu, K. Domke, J.M. Campina, N. Garcia-Arraez, E. Herrero, Abstr. Pap. Am. Chem. Soc., 225 (2003) 448.

[53] K. Domke, E. Herrero, A. Rodes, J.M. Feliu, J. Electroanal. Chem., 552 (2003) 115.

[54] N. Garcia-Araez, V. Climent, E. Herrero, J.M. Feliu, Surf. Sci., 560 (2004) 269.

[55] C. Buso-Rogero, E. Herrero, J. Bandlow, A. Comas-Vives, T. Jacob, Phys. Chem. Chem. Phys., (2013).

[56] R.M. Arán-Ais, M.C. Figueiredo, F.J. Vidal-Iglesias, V. Climent, E. Herrero, J.M. Feliu, Electrochim. Acta, 58 (2011) 184.

[57] S.C. Chang, L.W.H. Leung, M.J. Weaver, J. Phys. Chem., 93 (1989) 5341.

[58] C. Buso-Rogero, E. Herrero, J. Bandlow, A. Comas-Vives, T. Jacob, Phys. Chem. Chem. Phys., 15 (2013) 18671.

[59] S. Trasatti, Electrochim. Acta, 36 (1991) 1659.

[60] J. Lecoeur, J. Andro, R. Parsons, Surf. Sci., 114 (1982) 320.

[61] G.L. Beltramo, H. Ibach, M. Giesen, Surf. Sci., 601 (2007) 1876.

[62] N.P. Lebedeva, M.T.M. Koper, J.M. Feliu, R.A. van Santen, J. Phys. Chem. B, 106 (2002) 12938.

[63] K. Sashikata, T. Sugata, M. Sugimasa, K. Itaya, Langmuir, 14 (1998) 2896.

[64] L.A. Kibler, A. Cuesta, M. Kleinert, D.M. Kolb, J. Electroanal. Chem., 484 (2000) 73. 
Table 1. Binding energy for $\mathrm{Bi}$ and $\mathrm{Cu}$ atoms on the different sites for the $\mathrm{Pt}(553)$ surface.

\begin{tabular}{|l|r|r|}
\hline \multirow{2}{*}{ Site } & \multicolumn{2}{|l|}{ Binding energy/eV } \\
\cline { 2 - 3 } & \multicolumn{1}{|l|}{ Bi } & \multicolumn{1}{l|}{ Cu } \\
\hline fcc1 & 3.04 & 2.67 \\
\hline fcc2 & 3.10 & 2.67 \\
\hline fcc3 & 3.06 & 2.68 \\
\hline fcc4 & 3.52 & 3.17 \\
\hline hcp1 & 3.05 & 2.66 \\
\hline hcp2 & 3.04 & 2.64 \\
\hline hcp3 & 3.02 & 2.64 \\
\hline
\end{tabular}

Table 2. Binding energy for $\mathrm{Bi}$ and $\mathrm{Cu}$ atoms on the different sites for the $\mathrm{Pt}(711)$ surface.

\begin{tabular}{|l|r|r|}
\hline \multirow{2}{*}{ Site } & \multicolumn{2}{|l|}{ Binding energy/eV } \\
\cline { 2 - 3 } & \multicolumn{1}{|l|}{ Bi } & Cu \\
\hline $\mathrm{H} 1$ & 3.74 & 3.20 \\
\hline $\mathrm{H} 2$ & 3.80 & 3.22 \\
\hline $\mathrm{H} 3$ & 3.77 & 3.37 \\
\hline $\mathrm{H}^{*}$ & 3.35 & \\
\hline
\end{tabular}


Table 3. Binding energy for $\mathrm{OH}$ on different surfaces.

\begin{tabular}{|c|c|c|c|c|c|}
\hline \multicolumn{2}{|r|}{$\operatorname{Pt}(100)$} & \multicolumn{2}{|c|}{$\operatorname{Pt}(510)$} & \multicolumn{2}{|r|}{$\operatorname{Pt}(711)$} \\
\hline Site & Binding $[\mathrm{eV}]$ & Site & Binding $[\mathrm{eV}]$ & Site & Binding [eV] \\
\hline $\mathrm{T}$ & 2.17 & T1i & 2.55 & T1i & 2.36 \\
\hline B & 2.59 & T1o & 2.59 & T2o & 2.40 \\
\hline & & T2o & 2.19 & $\mathrm{~T} 2 \mathrm{i}$ & 2.13 \\
\hline & & $\mathrm{T} 3 \mathrm{i}$ & 2.13 & T2o & 2.11 \\
\hline & & T3o & 2.12 & $\mathrm{~T} 3 \mathrm{i}$ & 2.16 \\
\hline & & $\mathrm{T} 4 \mathrm{i}$ & 2.21 & T3o & 2.14 \\
\hline & & T4o & 2.21 & B1i & 2,80 \\
\hline & & $\mathrm{B} 12 \mathrm{i}$ & 2.68 & B1o & 2.81 \\
\hline & & B12o & 2.63 & $\mathrm{~B} 2 \mathrm{i}$ & 2.53 \\
\hline & & B23i & 2.55 & B2o & 2.51 \\
\hline & & B23o & 2.53 & B3i & 2.58 \\
\hline & & B34i & 2.61 & B3o & 2.55 \\
\hline & & B34o & 2.60 & B12 & 2.55 \\
\hline & & $\mathrm{B} 45 \mathrm{i}$ & 2.52 & B23 & 2.50 \\
\hline & & B45o & 2.52 & B34 & 2.27 \\
\hline
\end{tabular}


Table 4. Binding energy for $\mathrm{CO}$ on different surfaces.

\begin{tabular}{|c|c|c|c|c|c|}
\hline \multicolumn{2}{|c|}{$\operatorname{Pt}(100)$} & \multicolumn{2}{|c|}{$\operatorname{Pt}(510)$} & \multicolumn{2}{|c|}{$\operatorname{Pt}(711)$} \\
\hline \begin{tabular}{|l|} 
Site \\
\end{tabular} & $\begin{array}{c}\text { Binding } \\
{[\mathrm{eV}]}\end{array}$ & Site & $\begin{array}{c}\text { Binding } \\
{[\mathrm{eV}]}\end{array}$ & Site & $\begin{array}{c}\text { Binding } \\
{[\mathrm{eV}]}\end{array}$ \\
\hline $\mathrm{T}$ & 1.72 & T1 & 1.93 & $\mathrm{~T} 1$ & 1.80 \\
\hline B & 1.77 & $\mathrm{~T} 2$ & 1.72 & T2 & 1.66 \\
\hline & & T3 & 1.61 & T3 & 1.67 \\
\hline & & T4 & 1.73 & B1 & 1.81 \\
\hline & & B12 & 1.76 & B2 & 1.72 \\
\hline & & B23 & 1.65 & B3 & 1.78 \\
\hline & & B34 & 1.79 & B12 & 1.71 \\
\hline & & B45 & 1.83 & B23 & 1.80 \\
\hline & & $\mathrm{B}^{*}$ & 1.76 & B34 & 1.68 \\
\hline & & & & $\mathrm{B}^{*}$ & 1.30 \\
\hline
\end{tabular}




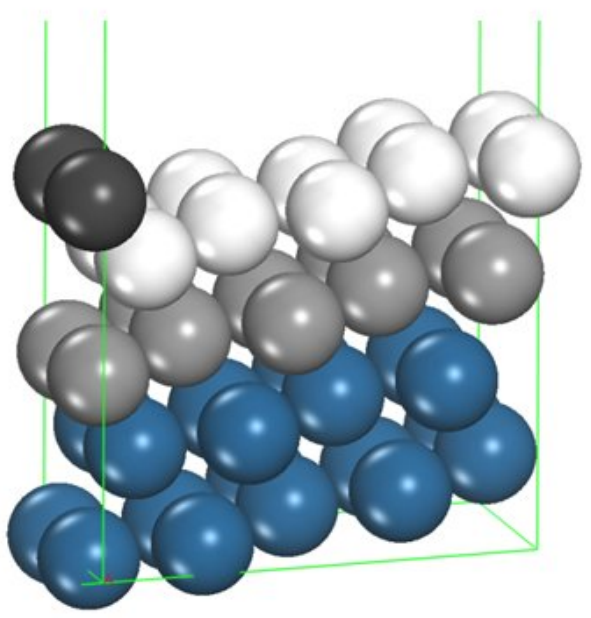

$\operatorname{Pt}\left(\begin{array}{l}5 \\ 5\end{array}\right)$

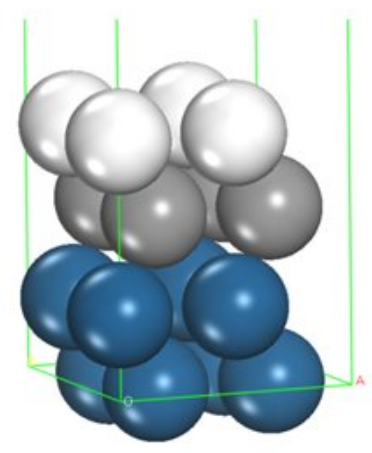

$\operatorname{Pt}\left(\begin{array}{lll}1 & 0 & 0\end{array}\right)$

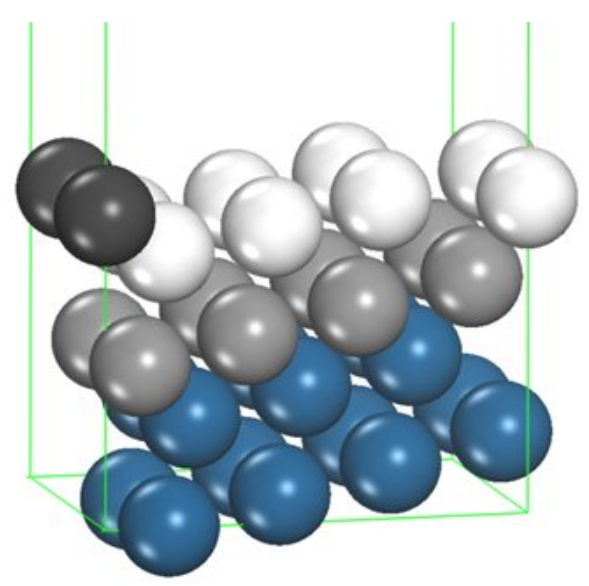

$\operatorname{Pt}\left(7 \begin{array}{ll}1 & 1\end{array}\right)$

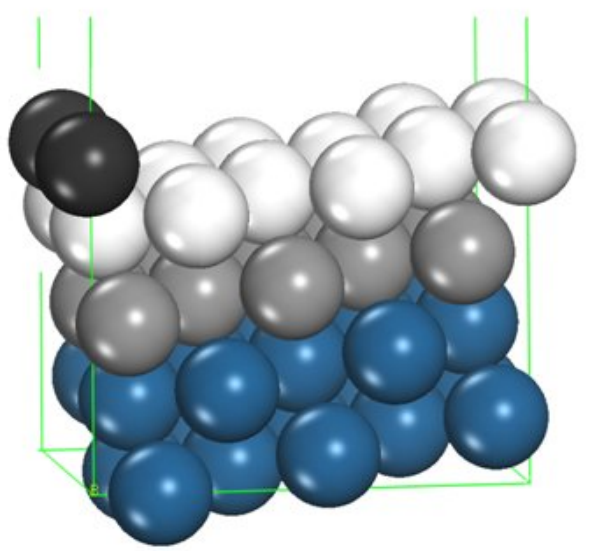

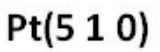

Figure 1. Periodic supercells used in the DFT calculations. The blue atoms were frozen in their bulk crystal locations, whereas the white and gray atoms were allowed to relax, with the adsorbates, during the calculations. In order to facilitate the visual perception of the step location, atoms being mirror images of others in their respective cell are also represented in black. 


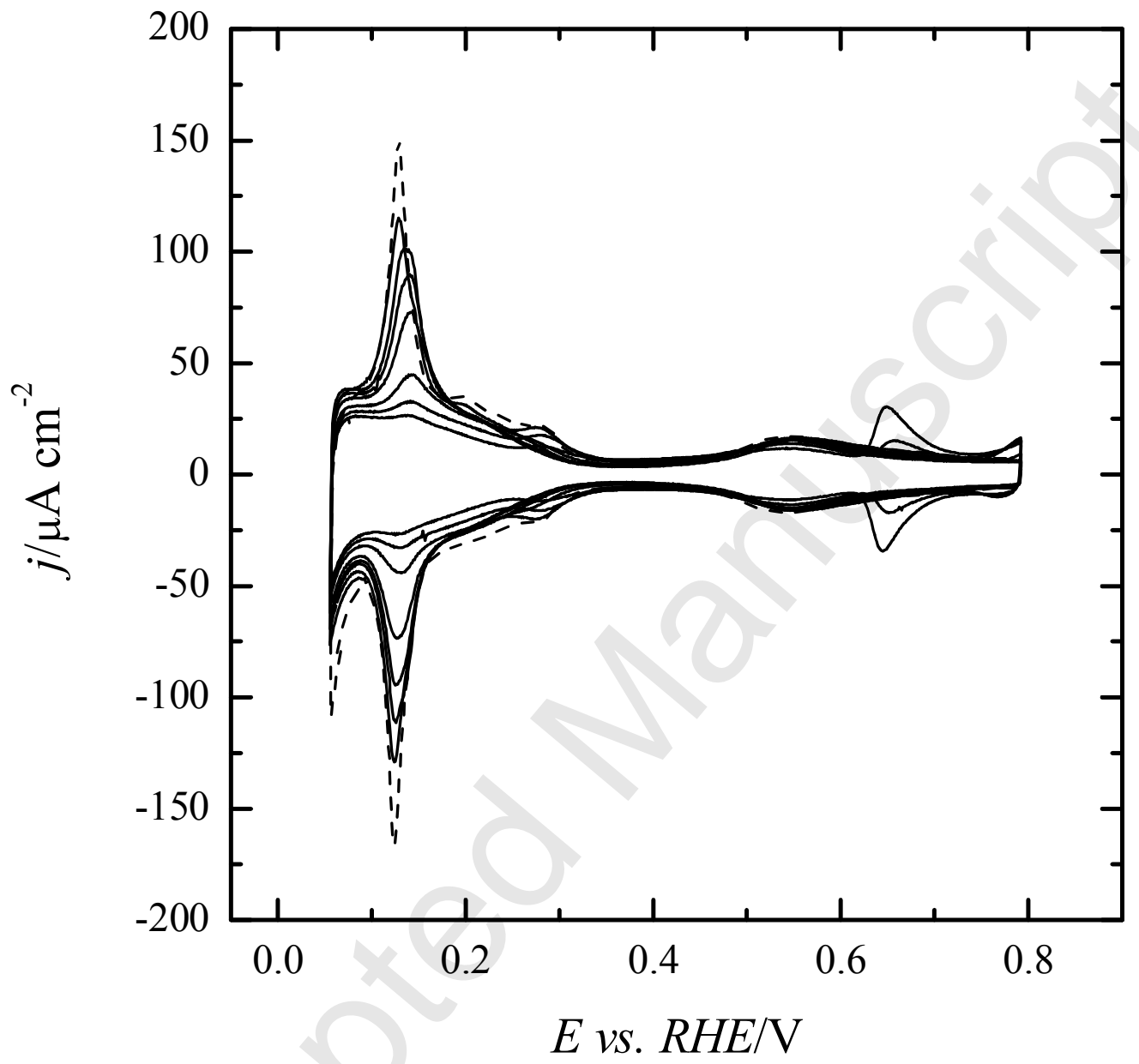

Figure 2. Bi deposition on the $\operatorname{Pt}(553)$ electrode from $0.5 \mathrm{M} \mathrm{H}_{2} \mathrm{SO}_{4}+10^{-5} \mathrm{Bi}^{+3}$. Cycles 1,2 , $3,4,5,10$ and 15 are shown. 


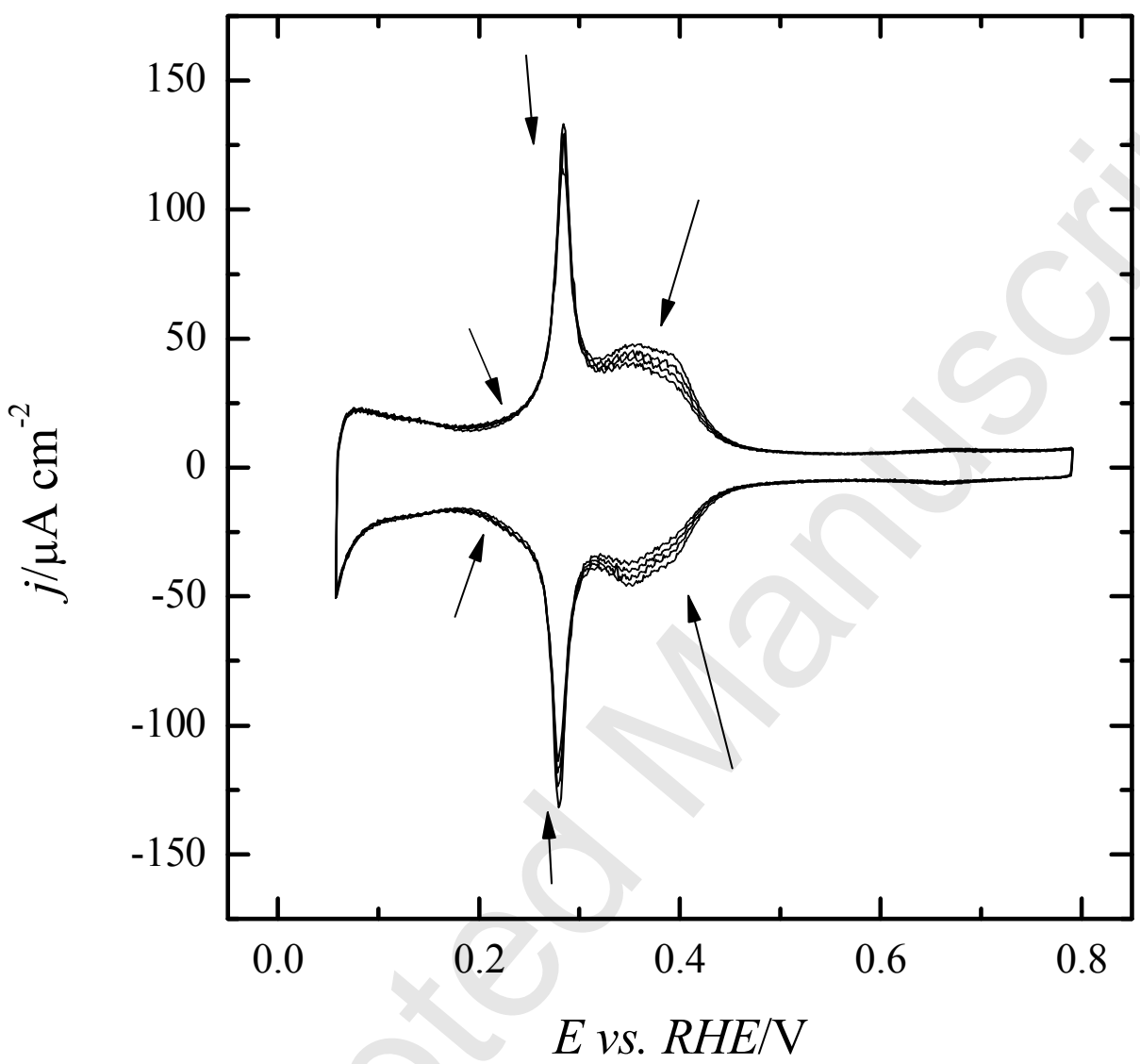

Figure 3. Bi deposition on the $\operatorname{Pt}\left(\begin{array}{lll}1 & 1 & 1\end{array}\right)$ electrode from $0.5 \mathrm{M} \mathrm{H}_{2} \mathrm{SO}_{4}+10^{-2} \mathrm{Bi}^{+3}$. Scans 1,10 , 20 and 30 are shown. 
$\mathbf{A}$

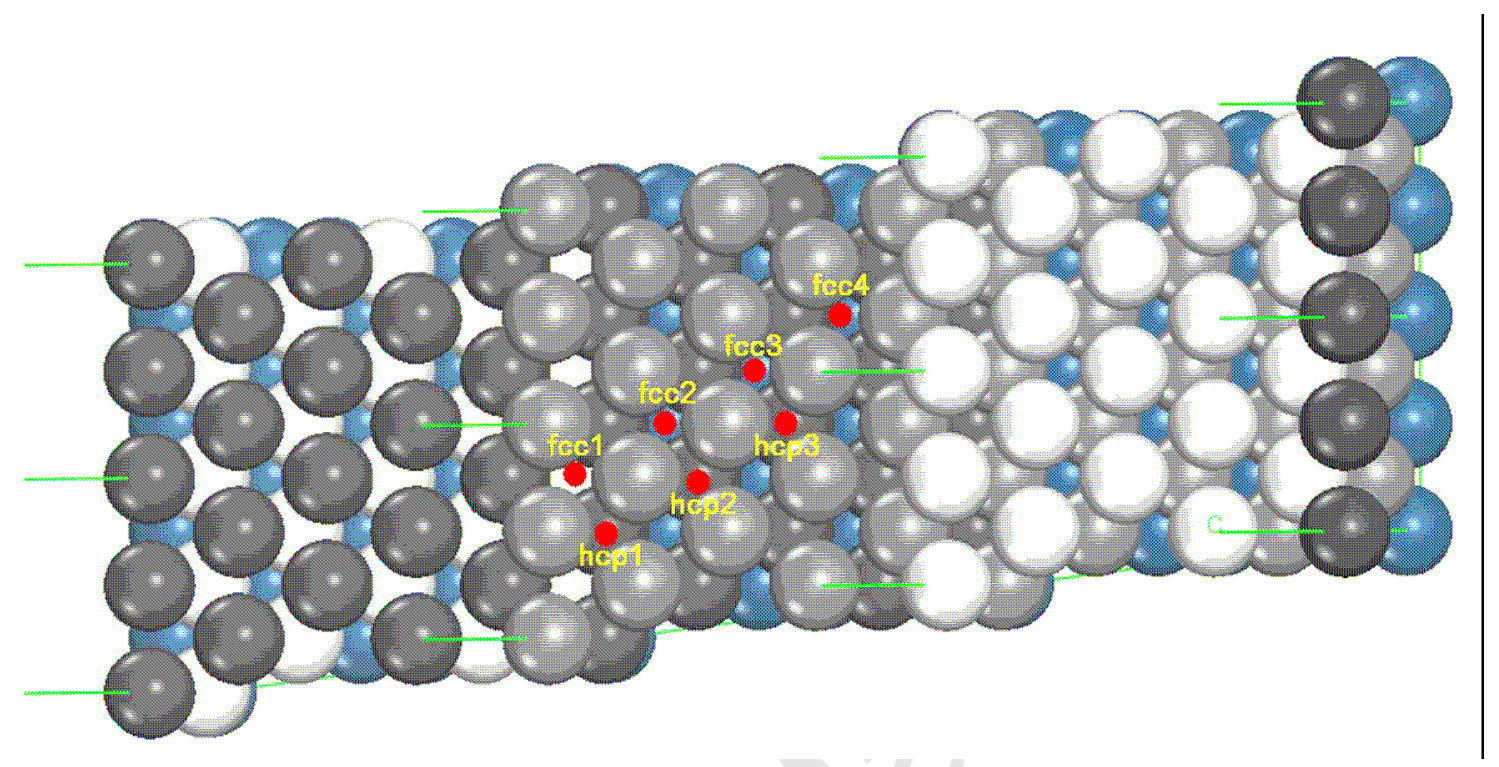

B

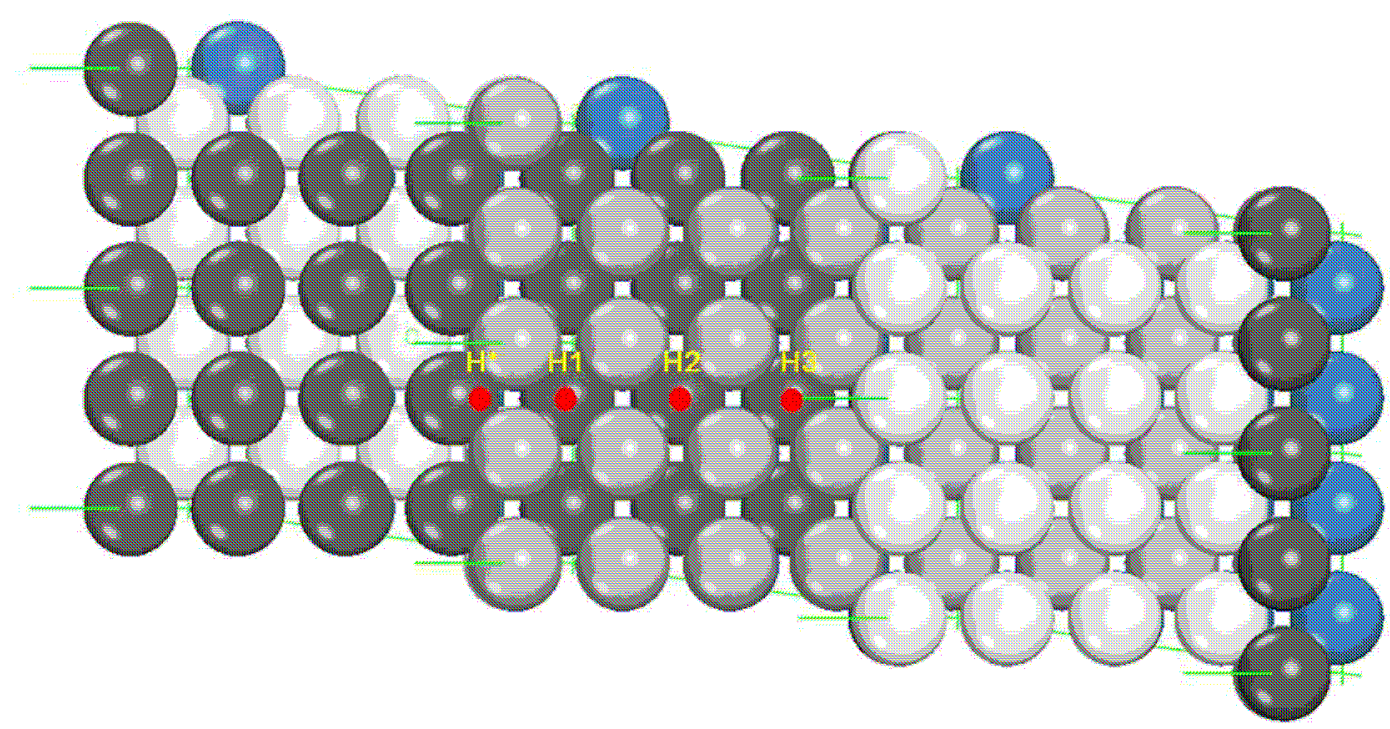

Figure 4. Site identification for the deposition of $\mathrm{Bi}$ or $\mathrm{Cu}$ on (A) the $\mathrm{Pt}(553)$ and (B) $\mathrm{Pt}(711)$ surfaces. 
A

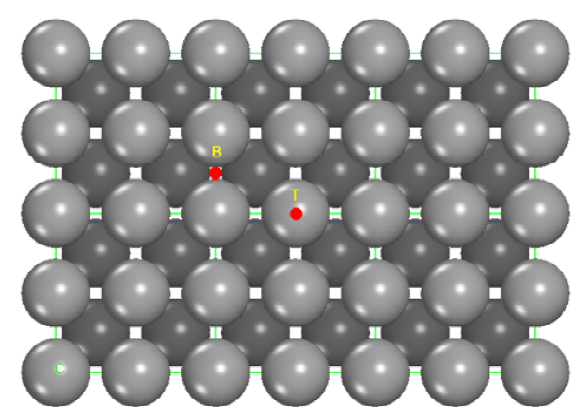

B

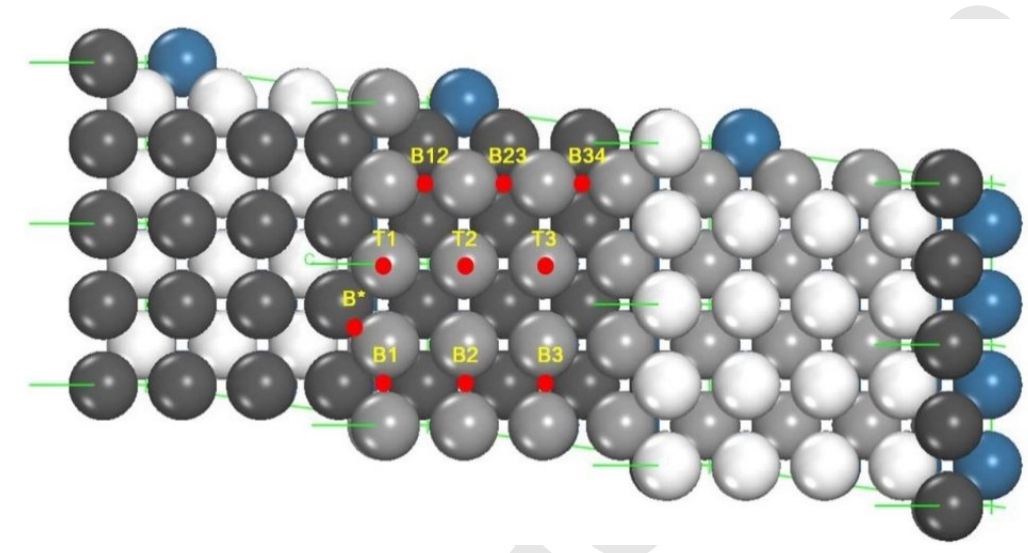

C

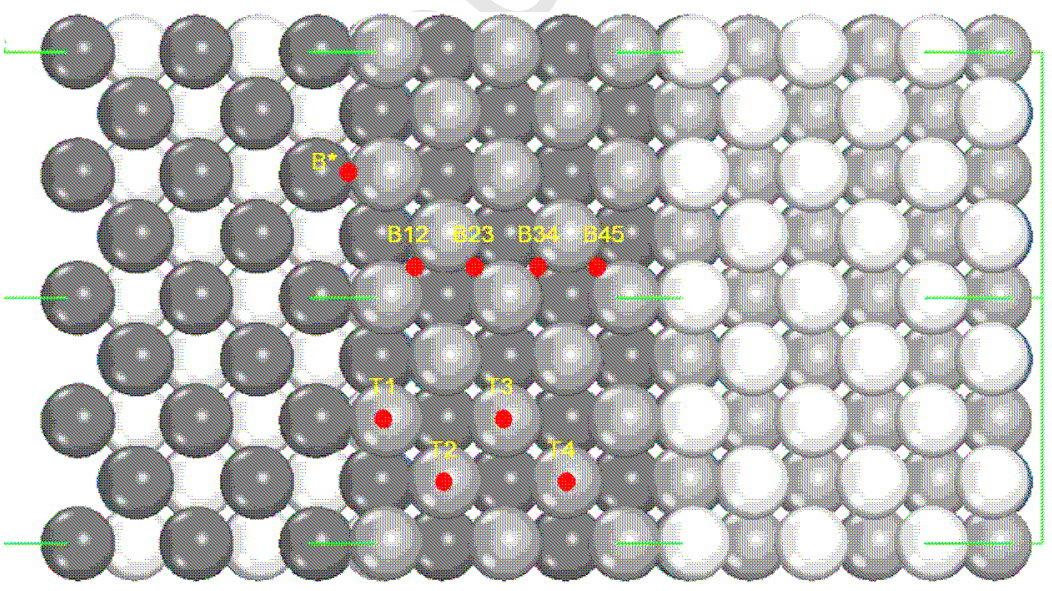


Figure 5. Site identification for the adsorption of $\mathrm{OH}$ or $\mathrm{CO}$ on (A) the $\operatorname{Pt}(100)$, (B) $\operatorname{Pt}(711)$ and (C) $\operatorname{Pt}(510)$ surfaces. 


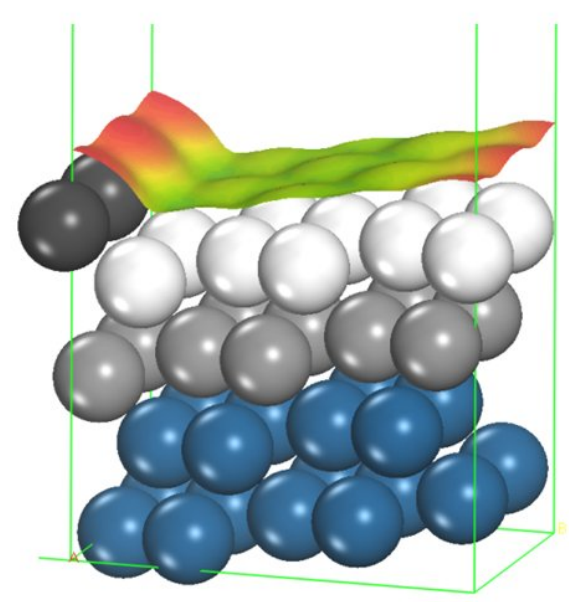

Pt(5 5 3)

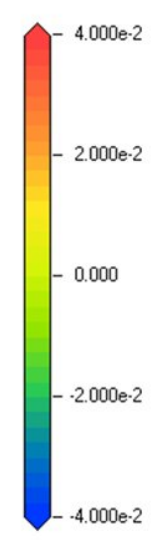

Pt(71 1)

Figure 6. Electrostatic potentials $[\mathrm{Ha} / \mathrm{e}]$ mapped on electron density isosurfaces, both of them corresponding to the density value $\rho=0.01 \mathrm{e} / \AA^{3}$. 